\title{
Patients With Congenital Myasthenia Associated with End-Plate Acetylcholinesterase Deficiency Show Normal Sequence, mRNA Splicing, and Assembly of Catalytic Subunits
}

\author{
Shelley Camp, * Suzanne Bon, ${ }^{\star}$ Ying Li, * Damon K. Getman, * Andrew G. Engel, ${ }^{\mathbf{5}}$ Jean Massoulié, ${ }^{\ddagger}$ and Palmer Taylor \\ ${ }^{*}$ Department of Pharmacology, University of California, San Diego, La Jolla, California 92093-0636; ${ }^{\ddagger}$ Laboratoire de Neurobiologie, \\ Ecole Normale Superieure, 75230 Paris, Cedex 05, France; and ${ }^{\S}$ Department of Neurology, Mayo Clinic, Rochester, Minnesota 55905
}

\begin{abstract}
A congenital myasthenic condition has been described in several patients characterized by a deficiency in end-plate acetylcholinesterase (AChE). The characteristic form of $\mathrm{AChE}$ in the end-plate basal lamina has the catalytic subunits disulfide linked to a collagen-like tail unit. Southern analysis of the gene encoding the catalytic subunits revealed no differences between patient and control DNA. Genomic DNA clones covering exon 4 and the alternatively spliced exons 5 and 6 were analyzed by nuclease protection and sequencing. Although allelic differences were detected between controls, we found no differences in exonic and intronic areas that might yield distinctive splicing patterns in patients and controls. The $A C H E$ gene was cloned from genomic libraries from a patient and a control. Transfection of the cloned genes revealed identical species of mRNA and expressed AChE. Cotransfection of the genes expressing the catalytic subunits with a cDNA from Torpedo encoding the tail unit yielded asymmetric species that require assembly of catalytic subunits and tail unit. Thus the catalytic subunits of AChE expressed in the congenital myasthenic syndrome appear identical in sequence, arise from similar splicing patterns, and assemble normally with a tail unit to form a heteromeric species. (J. Clin. Invest. 1995. 95:333-340.) Key words: - myasthenic syndrome - congenital acetylcholinesterase deficiency $\bullet$ acetylcholinesterase species • alternative mRNA processing • collagenous subunit
\end{abstract}

\section{Introduction}

In 1977 Engel et al. (1) reported a patient with a myasthenic syndrome associated with a deficiency of end-plate acetylcholinesterase (AChE). ${ }^{1}$ Recently, other patients with similar my-

Address correspondence to Palmer Taylor, Ph.D., Department of Pharmacology, University of California, San Diego, 9500 Gilman Drive, La Jolla, CA 92093. Phone: 619-534-1366; FAX: 619-534-8248. Y. Li's present address is Cardiovascular Division, Brigham and Womens General Hospital, 75 Francis Street, Boston, MA 02115.

Received for publication 24 June 1994 and in revised form 19 September 1994

1. Abbreviations used in this paper: $\mathrm{AChE}$, aetylcholinesterase; $\mathrm{EAD}$, congenital myasthemia associated with end-plate AChE deficiency; HEK, human embryonic kidney cells; PIPLC, phosphatidylinositol-specific phospholipase $\mathrm{C}$.

J. Clin. Invest.

(C) The American Society for Clinical Investigation, Inc.

0021-9738/95/01/0333/08 $\$ 2.00$

Volume 95, January 1995, 333-340 asthenic disorders associated with abnormalities in AChE histochemistry and activity have been described $(2,3)$. The absence of antiacetylcholine receptor antibodies, an onset of the syndrome in early life, and a familial incidence further categorize the disorder as congenital.

Patients with congenital myasthenia associated with endplate $\mathrm{AChE}$ deficiency (EAD) show an absence of end-plate AChE by light microscopic, cytochemical electron microscopic, and immunocytochemical criteria in fresh and fixed muscle (24). Owing to the deficiency in the enzyme at the end plate, the patients do not benefit from anticholinesterase therapy. Characteristically, electrophysiological measurements show a decremental electromyographic response, prolonged end-plate currents, reduced release of acetylcholine quanta elicited by nerve impulses, and normal channel opening kinetics. Presynaptic terminals are reduced in size and often encased in Schwann cells (3). It has been suggested that the changes in nerve terminal size and quantal release might be secondary to the diminution in end-plate AChE activity (3).

Four of the patients studied show the virtual absence of the dimensionally asymmetric collagen-tailed forms of $\mathrm{AChE}$ that sediment at 16 and $14 \mathrm{~S}$. However, one patient has detectable extracted asymmetric AChE, but as in the others, has no AChE deposited in the synaptic space (3). No differences in catalytic constants or deficiencies in erythrocyte AChE have been detected in any of the patients.

In humans, a single $A C H E$ gene, located at $7 \mathrm{q} 22(5,6)$, encodes the catalytic subunits of all of the known molecular species of AChE. The structural diversity of the molecular forms of $\mathrm{AChE}$ arises from alternative mRNA splicing yielding three distinct carboxyl termini (7-9) (see Fig. 1). In humans and other mammals, exons 2,3 , and 4 , which encode the essential catalytic residues and most of the open reading frame, are invariant and account for the identical catalytic properties of all molecular species of $\mathrm{AChE}(10,11)$. The distinct carboxyl termini allow the enzyme to be expressed as ( $a$ ) hydrophilic monomers; (b) homomeric monomers, dimers, and tetramers that vary in hydrophobicity through attachment of a fatty acid or exposure of an amphipathic helix; (c) glycophospholipid-linked species; and $(d)$ heteromeric oligomers that disulfide link either to a filamentous triple-helical collagen unit or a lipid-linked subunit (10-12). Reading through the retained intron in the gene $3^{\prime}$ of exon 4 gives rise to hydrophilic monomers, splicing to exon 5 yields the glycophospholipid-linked species, and splicing to exon 6 gives rise to all of the other molecular forms. Hence, mRNA splicing governs the structural diversity of AChE, but the multiplicity of $\mathrm{AChE}$ species is further enhanced by posttranslational differences in subunit assembly $(12,13)$.

Recently, Soreq and colleagues (14) published a partial sequence of a human genomic $A C H E$ clone, and from the sequence argued that retention of the intron between exons 4 and 5 would leave the glycophospholipid anchor signal in-frame. Although 
Table I. Lymphocyte DNA Origins: Congenital Myasthenia with EAD and Control Subjects

\begin{tabular}{|c|c|c|c|c|}
\hline Subject & Age & Sex & Asymmetric AChE & Other features* \\
\hline EAD-1 & $16 \mathrm{yr}$ & Male & Absent in extracts and synapse & Original patient (1) \\
\hline EAD-2 & $12 \mathrm{yr}$ & Female & Absent in extracts and synapse & $A C H E$ gene cloned from a size-selected library (2) \\
\hline EAD-3 & $8 \mathrm{yr}$ & Female & Absent in extracts and synapse & Sister of EAD-2 (2) \\
\hline EAD-4 & $4 \mathrm{mo}$ & Male & Absent in extracts and synapse & Severe symptoms at birth (2) \\
\hline EAD-5 & $43 \mathrm{yr}$ & Male & Present in extracts; absent in the synapse & Attachment of tail unit to basal lamina may be affected (2) \\
\hline Control 1 & & Placenta & 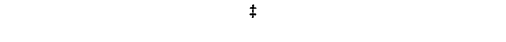 & $A C H E$ gene cloned from a placental cosmid library \\
\hline Control 2 & $40 \mathrm{yr}$ & Male & $\ddagger$ & EBV transformed lymphocytes \\
\hline Control 3 & $40 \mathrm{yr}$ & Female & $\ddagger$ & Control DNA for our laboratory studies \\
\hline
\end{tabular}

* Reference numbers in parentheses. ${ }^{\ddagger}$ No neuromuscular abnormalities have been described, but muscle biopsies have not been taken.

previously published human $A C H E$ sequences were not acknowledged (14), this sequence differs from that recorded in Genebank (Dec. 18, 1991) by $\mathrm{Li}$ and colleagues by dropping two guanosines to effect a frame shift. Our sequencing of this region in genomic clones from two origins, in two directions and in the presence and absence of dITP, clearly reveals the two guanosines in accord with the sequence of $\mathrm{Li}$ (accession number M76540). Hence, retention of the intron between exons 4 and 5 in human will lead to an interposed translation termination signal as well as the glycophospholipid signal remaining out of frame. This is also the case in mouse $(12,15)$ and rat $(16)$.

The heteromeric forms containing the disulfide-linked collagen unit are localized primarily in the basal lamina of motor end-plates; these are the $\mathrm{AChE}$ forms that are deficient at endplates of patients with the congenital myasthenic syndrome (13 ). Structurally, the end-plate species are composed of one to three tetramers of catalytic subunits; each tetramer is disulfidelinked to one of three strands of a collagen-containing structural subunit. The molecular mass of the fully assembled entity containing 12 catalytic subunits approaches $10^{6} \mathrm{D}(10,11)$.

A cDNA encoding the collagen-containing subunit has been cloned from the Torpedo electric organ (17). It encodes noncollagenous sequences at its amino- and carboxyl termini that flank an intervening collagen-like sequence. Cys 580 near the carboxyl terminus of the catalytic subunit $(7,18)$ forms an intersubunit disulfide bond with a cysteine in the amino-terminal region of the tail unit $(17,19)$.

In those EAD patients who do not express the asymmetric forms of AChE, the abnormality could arise from a structural change in either the catalytic or tail unit, abnormal splicing within the catalytic unit, or a deficiency in the overall assembly of disulfide-linked subunits. Characterization of the human $A C H E$ gene has enabled us to examine whether abnormalities in catalytic subunit structure, splicing, or assembly of the gene products are responsible for the end-plate $\mathrm{AChE}$ deficiency.

\section{Methods}

Patient selection and samples. Over the past $8 \mathrm{y}$, the patients listed in Table I have been followed at the Mayo Clinic. Blood samples were taken by venipuncture, and DNA was isolated from the separated lymphocytes. The lymphocytes were immortalized by EBV transformation and maintained in culture (20) in order to obtain accessible sources of DNA and RNA for these and future studies.

PCR amplification of genomic DNA from lymphocytes. Reactions contained $50 \mathrm{mM} \mathrm{KC1}, 10 \mathrm{mM}$ Tris- $\mathrm{HCl}, \mathrm{pH} 8.3,1.0 \mathrm{mM} \mathrm{MgCl}$, $0.1 \%$ gelatin, $200 \mu \mathrm{M}$ each $\mathrm{dNTP}, 0.26 \mu \mathrm{M}$ each oligonucleotide primer,
$2.5 \mathrm{U}$ of Taq DNA polymerase (Perkin-Elmer-Cetus, Norwalk, CT), and $1 \mu \mathrm{g}$ of DNA in $100 \mu \mathrm{l}$ volume. The thermal profile involved 10 cycles of $1 \mathrm{~min}$ at $94^{\circ} \mathrm{C}, 2 \mathrm{~min}$ at $63^{\circ} \mathrm{C}, 3 \mathrm{~min}$ at $72^{\circ} \mathrm{C}$ followed by 30 cycles of $1 \mathrm{~min}$ at $94^{\circ} \mathrm{C}$ and $4 \mathrm{~min}$ at $72^{\circ} \mathrm{C}$. Electrophoresis of one-tenth of each reaction on a $1.5 \%$ agarose gel, blotting to nitrocellulose, and hybridization with a ${ }^{32} \mathrm{P}$-labeled oligonucleotide unique to the amplified region identified the amplified genomic fragment. The hybridizing band was isolated from a $1.5 \%$ agarose gel and reamplified, digested with specific restriction enzymes, and cloned into both $\mathrm{M}-13 \mathrm{mp} 18$ and pBluescript II for further analysis.

Restriction analysis and sequencing. Human genomic clones that were used as controls in these experiments were isolated from a Cosmid library as described previously $(12,13)$. DNA sequencing used the dideoxy method using Sequenase T7 polymerase and protocols from United States Biochemical Corp. (Cleveland, $\mathrm{OH}$ ). In cases where compression was evident, dITP was used in the sequencing gels. Restriction fragment subcloning into $\mathrm{M}-13$ and sequence specific oligonucleotide primers were used to obtain complete sequence in both directions.

Expression of patient and control genomic DNA in human embryonic kidney (HEK)-293 cells. The expression plasmid pCMV-4 (21), which includes the cytomegalovirus promoter and a translational enhancer, was used to express a genomic 4.7-kb SstII fragment from the human $A C H E$ gene. This genomic fragment contains the coding exons necessary to account for all of the splice variants of the catalytic subunit. DNA from both control and patient libraries was used. HEK cells at $1.5 \times 10^{6}$ cells $/ 10 \mathrm{~cm}$ dish were transfected with these plasmids with $\mathrm{Ca}_{3}\left(\mathrm{PO}_{4}\right)_{2}$ precipitation $(12,13)$. RNA from transfected cells was harvested $24 \mathrm{~h}$ posttransfection, whereas expression of AChE activity was monitored between 48 and $72 \mathrm{~h}$ after transfection.

COS cells were also transiently transfected with the same plasmid using DEAE dextran $(17,19)$. Cotransfection of these plasmids encoding the catalytic subunits with a plasmid containing a cDNA insert encoding a subunit of the tail unit from Torpedo mamorata and characterization of the expressed enzyme used similar procedures $(20,23)$.

RNase protection assays. AChE cDNA clones were constructed from genomic cosmid clones by loop-out mutagenesis using standard protocols (24). cDNA and genomic subclones in pBluescript II plasmids were used as templates for in vitro transcription to obtain RNA probes. HEK cells were transiently transfected as described. At $24 \mathrm{~h}$ after transfection, RNA was harvested and isolated by the method of Chomczynski and Sacchi (25), treated to remove contaminating DNA, and then used for RNase protection assays. Protection experiments were performed essentially according to the method of Ausubel et al. (24) using $10 \mu \mathrm{g} /$ $\mathrm{ml}$ RNase $\mathrm{A}$ and $150 \mathrm{U} / \mathrm{ml}$ RNase T1. Hybridization of mRNA with the labeled probe was conducted at $60^{\circ} \mathrm{C}$ overnight. RNase digestion was carried out at $30^{\circ} \mathrm{C}$ for $30 \mathrm{~min}$.

Construction of a size-selected library from genomic DNA isolated from Epstein-Barr immortalized patient lymphocytes. Genomic DNA was isolated from Epstein-Barr transformed cells in culture using standard techniques (24). The DNA was digested completely with Bg1II and was then run on a $0.8 \%$ agarose gel. A band corresponding to the 


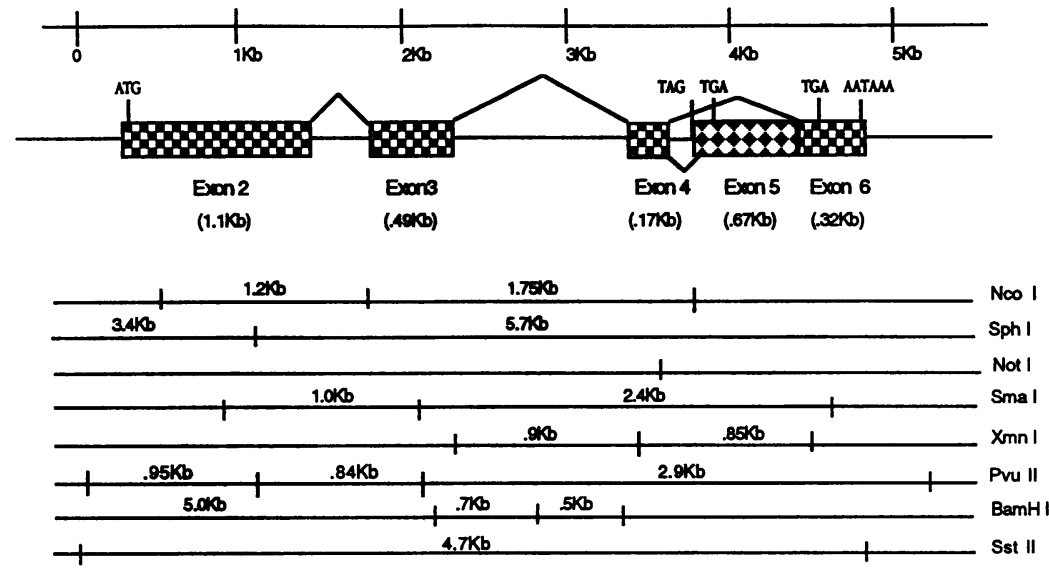

Figure 1. Restriction map of the human $A C H E$ gene. Standard restriction analysis was used to characterize a 15-kb BglII genomic subclone of a 35-kb clone isolated from a human placental cosmid library. Invariant splices are shown by solid lines connecting exons 2 and 3, 3 and 4; alternative splices connecting exon 4 with exons 5 and 6 are also designated. ATG represents the initiation methionine. TAG and TGA represent stop codons. AATAAA is the polyadenylation signal. Below is a restriction fragment map deduced from analyses shown in Fig. $2 A$ and $B$. Fragment sizes are not shown when restriction sites extend beyond the limits of either the control cosmid or the patient genomic clones. region between 9 and $16 \mathrm{~kb}$ was excised, partially purified with Geneclean (Bio-101 Products, La Jolla, CA), and ligated with BamHI cut $\lambda$-arms (Stratagene, La Jolla, CA). Packaging and plating were carried out according to Stratagene protocols. Screening was accomplished using the 4.7-kb SstII fragment from the human genomic cosmid clone that was labeled by random priming (26). Selected phage were analyzed by restriction digestion conducted in parallel with the cosmid clone as well as by sequencing.

SI nuclease analysis of control and patient DNA. Patient and control DNAs were obtained directly from lymphocyte genomic DNA by PCR amplification and were then cloned into $\mathrm{M}-13$ in identical orientations. A sequence specific primer and radiolabeled nucleotides were used to generate a single strand complementary to the M-13 template to be tested. The resulting duplex was cut with a restriction enzyme in the M-13 polylinker and then denatured, allowing the single-stranded probe to be isolated on an agarose gel. The labeled probe and M-13 template were hybridized overnight at $50^{\circ} \mathrm{C}$ and then digested with $\mathrm{S} 1$ nuclease according to standard techniques (24). The digested samples were run on a alkaline agarose gel, dried, and exposed to film.

Sucrose density gradient centrifugation and AChE expressed from cells transfected with genomic clones. After transfection of HEK cells with the pCMV-4 plasmid as described above, dishes were rinsed with phosphate-buffered saline (PBS) and then covered with Dulbecco's modified Eagle's medium in the absence of serum. After 48-72 h, media and cells were collected separately. The media was loaded directly onto 5-20\% sucrose density gradients. The cells were washed several times with PBS and then either extracted by sonication in 1\% Triton $\mathrm{X}-100,1 \mathrm{M} \mathrm{NaCl}, 40 \mathrm{mM} \mathrm{MgCl}{ }_{2}, 25 \mathrm{mM}$ Tris- $\mathrm{HCl}, \mathrm{pH} 8$ and spun $10 \mathrm{~min}$ at $14,000 \mathrm{rpm}$ to remove particulate matter or treated with phosphatidylinositol-specific phospholipase C (PIPLC), a gift of Dr Martin Low (Columbia University, New York) for $10 \mathrm{~min}$ in PBS at $37^{\circ} \mathrm{C}$ and spun at $14,000 \mathrm{rpm}$ for $10 \mathrm{~min}$ to remove cellular material before loading onto the gradients. Extracts obtained from cells expressing both the catalytic and tail units were treated with collagenase type III (Advanced Biofactors, Lynbrook, NY), as described previously $(19,23)$. The $5-20 \%$ sucrose density gradients contained $1 \%$ Triton $\mathrm{X}-100,1 \mathrm{M} \mathrm{NaCl}, 40 \mathrm{mM} \mathrm{MgCl}$, and $25 \mathrm{mM}$ Tris- $\mathrm{HCl}, \mathrm{pH}$ 8. The gradients were centrifuged at $40,000 \mathrm{rpm}$ for either 12 or $20 \mathrm{~h}$ at $4^{\circ} \mathrm{C}$ in an SW-41 rotor. $S$ values were calculated from the relative positions of carbonic anhydrase (3.3 S), alkaline phosphatase (6.1 S), and catalase (11.4 S), and $\beta$-galactosidase (16 S).

\section{Results}

Restriction analysis. A limited restriction map of the human $A C H E$ gene is shown in Fig. 1. Restriction fragment analyses of DNA isolated from patient lymphocytes and the cloned gene from one of the patients (EAD-2) are shown in Fig. 2, $A$ and
$B$. No differences in restriction fragment size were observed between patient and control digests; all of the restriction fragments could be accounted for as full or partial digests. Hence,
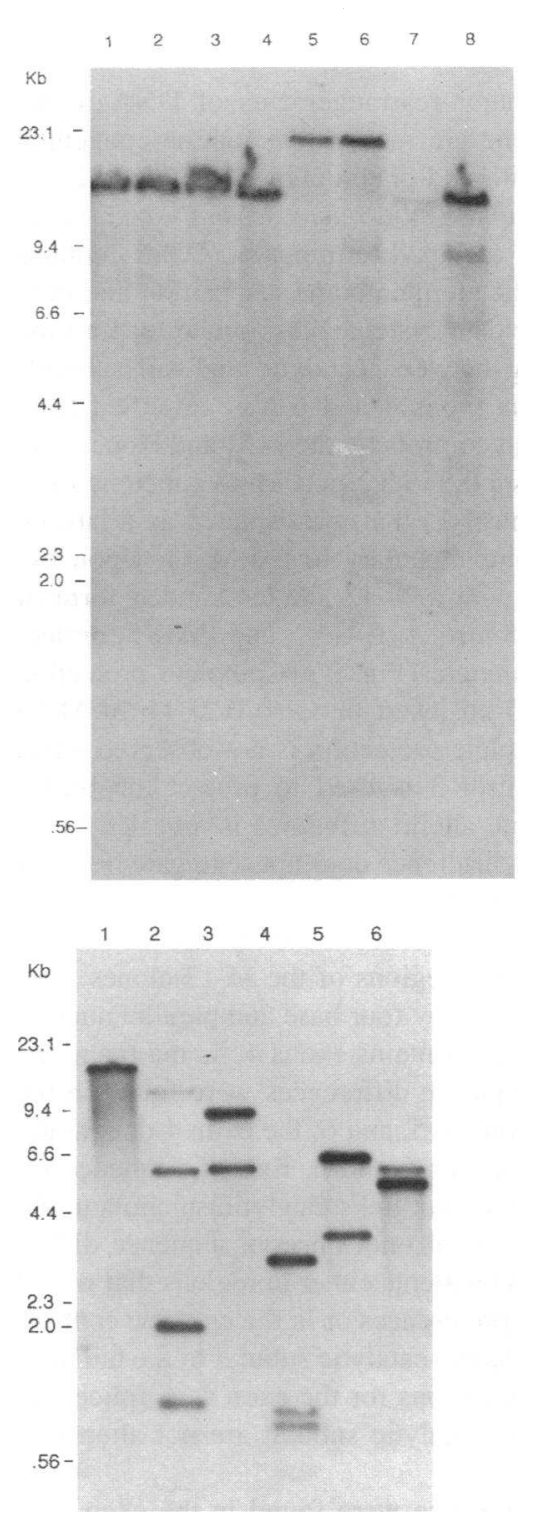

Figure 2. (A) Southern blot analysis of genomic DNA from EBV transformed cells obtained from patient blood samples. Lanes 1,5 , and 7, patient (EAD-4); lane 2, patient (EAD-2); lane 3 , patient (EAD-3); lanes 4,6 , and 8 , control-2. In lanes 1 through 4, DNA was digested with BglII, lanes 5 and 6 with EcoRI, lanes 7 and 8 , with HindIII. The blot was probed with a 4.7-kb SstII fragment of the human $A C H E$ gene that contains all of the coding exons. This probe was labeled by random priming. $(B)$ Southern blot analysis of the 15-kb BglII fragment subcloned from a clone selected from the patient EAD-2 size-selected library. The digests were as follows: Lane 1 , EcoRI; lane 2, NcoI; lane 3, NotI; lane 4, PvuII; lane 5, SphI; lane 6 , SstII. The blot was probed with a random primed 4.7-kb SstII fragment that contained all the coding exons from the human ACHE gene. Faint bands in lanes 2 and 6 arise from incomplete digestion. 


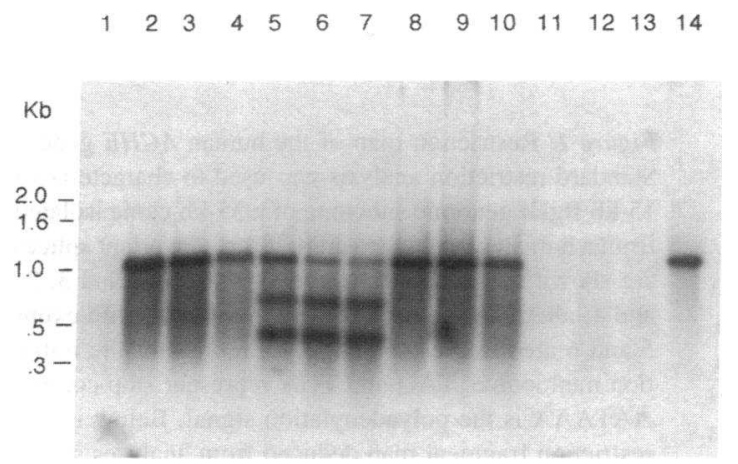

Figure 3. S1 nuclease analysis of control and patient DNA. The probe DNA is a $0.85-\mathrm{kb}$ XmnI M-13 subclone of the ACHE gene from EAD2 (see Table I and Fig. 1) that spans the region between exons 4 and 6. Patient and control DNAs were obtained directly from lymphocyte genomic DNA by PCR amplification and cloning into M-13. The radiolabeled EAD-2 probe was made from an M-13 template in the same orientation as the control samples. Lane 1 , probe alone $+\mathrm{S} 1$ nuclease; Lanes 2, 3, and 4, DNA from patient EAD-2; Lanes 5, 6, and 7, DNA from control 3; lanes 8, 9, and 10, DNA from patient EAD-3; Lanes 11,12 , and 13, DNA from control 3, opposite orientation in M13; Lane 14 , probe alone.

it seems unlikely that major rearrangements of DNA in the vicinity of the $A C H E$ gene are responsible for the congenital myasthenia associated with end-plate deficiency of AChE.

Amplification of genomic DNA, nuclease analysis, and sequencing. Since the very carboxyl terminus of AChE contains variable sequences that dictate membrane disposition and only the exon 4 to 6 splice yields a cysteine appropriate for forming intersubunit cross-linking between catalytic and tail subunits (18), the region between exons 4 and 6 was amplified from DNA of EAD patients and controls by the PCR and cloned into $\mathrm{M}-13$. The probe DNA is a $0.85-\mathrm{kb}$ XmnI M-13 subclone from a control individual (control 1) that was isolated as a labeled single-stranded probe complementary to the M-13. Upon hybridization of the probe with a M-13 single-stranded form of the genomic DNA from control 1, EAD-2, and EAD-3, protection was found to be complete (Fig. 3). Complete protection not only reflects the $0.85-\mathrm{kb}$ insert but also $0.25 \mathrm{~kb}$ of $\mathrm{M}-13$ sequence. However, complete protection is not observed when genomic DNA from control 3 is used to protect the probe. Hence, although a possible allelic difference is revealed by $S$ 1 nuclease protection, the difference does not segregate between patients and control individuals.

To investigate this potential sequence difference further, we sequenced the $0.85-\mathrm{kb} \mathrm{XmnI}$ regions of the M-13 clones from EAD-2, EAD-3, and control 3 by four base and parallel nucleotide sequencing. This region contains exons 4,5 , and 6 and the intervening intron. No sequence differences were found in the open reading frame of exons 4,5 , and 6 ; the exon 4 donor site; and the acceptor sites of exons 5 and 6 . Exon 6 sequence includes Cys 580, the cysteine that links catalytic subunits to the tail unit $(12,18)$. Hence, we do not observe sequence differences between controls and patients either in regions that would implicate altered splicing preferences or in the cysteine contributing the disulfide that links the catalytic subunit to the tail unit. Both the donor-acceptor positions for the exon 4-6 splice and the critical cysteine in the catalytic subunit are not altered in the patients.

Two differences in sequence were found in the exon 4-6

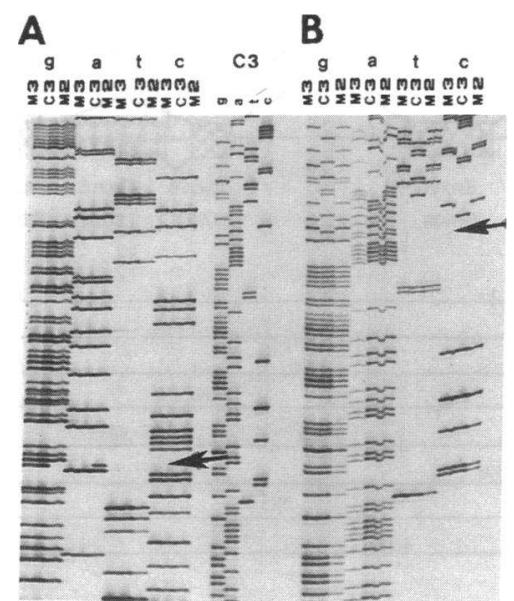

Figure 4. Dideoxy sequence analysis of control and EAD patient DNA in the region spanning exons 4 and $6 .(A)$ Sequence from a primer in exon 6 , the sequence shown is the complement strand which reads 5 ' into the intron. $(B) \mathrm{Se}$ quence from a primer located $150 \mathrm{bp} 5^{\prime}$ of the exon 6 splice acceptor, the sequence also reads $5^{\prime}$ into the intron. The arrows indicate sequence differences, notably a single base change in

EAD-2 and a 3-bp depletion that appeared in control 3. The 3-bp deletion did not occur in either control 1 or control 2 and was responsible for the two fragments seen in the S1-protection experiment (cf. Fig. 3). M2 and M3 represent patients EAD-2 and EAD-3, and C3 is control 3.

region (Fig. 4). Both are located in a noncoding region $3^{\prime}$ of the translated region of exon 5. The two differences appear as a 3-bp deletion $300 \mathrm{bp} \mathrm{5'}$ of the exon 6 acceptor in control 3 but not in control 1, EAD-2, or EAD-3 and a single bp substitution $10 \mathrm{bp} 5^{\prime}$ of the exon 6 splice acceptor in EAD-2 but not EAD-3. This points to an allelic difference between individuals that does not segregate with EAD. Only the 3-bp deletion is detected in the S-1 nuclease experiments. The positions of the two deletions are noted in Fig. 5.

Expression of genomic DNA from patients and control individuals. Restriction fragment analysis of the clone isolated from a cosmid library from a control DNA sample (17) (Fig. 1) enabled us to construct an appropriately size-selected library from a Bg1II digest of a sample of DNA from EAD-2. The isolated clone was characterized by restriction analysis (Fig. 2) and corresponding 4.7-kb SstII fragments from the cosmid clone (control 1) and the genomic clone (EAD-2) were placed behind the CMV promoter for expression (Fig. 5).

Transient transfections into HEK cells, which are initially devoid of detectable AChE mRNA or activity, yield characterizable gene products. The mRNA species were identified by mRNA protection using a BamHI-ApaI probe from genomic (unspliced) DNA and two cDNA probes reflecting the exon 46 splice. These labeled probes should detect the three potential splice options generated in the region of the gene between exons 4 and 6 (see Fig. 5). As shown in Fig. $6, A-C$, we observe that all three splice alternatives of the mRNA are generated in the transfected HEK cells. Importantly, there appear to be no differences in the relative population of mRNA species after gene transfections of EAD-2 and control 1.

We also examined by sedimentation in sucrose density gradients the molecular species of $\mathrm{AChE}$ generated after transfection of the genomic DNA clones into HEK cells. Individual species of AChE may be detected by their respective sedimentation coefficients, changes in sedimentation coefficient induced by Triton X-100 and Brij 96, and susceptibility to PIPLC (22). In other studies with mouse genomic DNA and cDNA clones, the species expressed from the genomic clones were compared with the molecular species of AChE formed after expression of three cDNA's in which retention of the intron after exon 4 , the exon 4 to exon 5 splice, and the exon 4 to exon 6 splice are dictated by the 


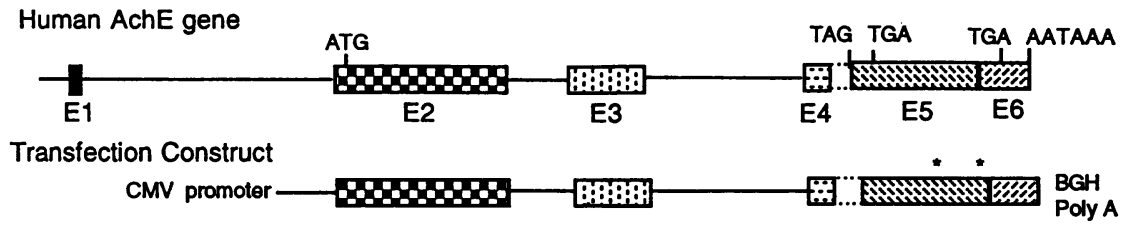

Possible RNA Splicing

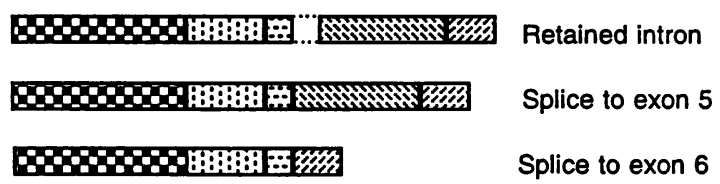

\begin{tabular}{|c|c|}
\hline Protected Species & Size \\
\hline BamH I-Apa I (P & A) \\
\hline $\begin{array}{l}\text { unspliced RNA } \\
\text { Exon } 4 \\
\text { Exon } 5\end{array}$ & $\begin{array}{l}420 \mathrm{bp} \\
170 \mathrm{bp} \\
158 \mathrm{bp}\end{array}$ \\
\hline BamH I-Sma I (F & be B) \\
\hline $\begin{array}{l}\text { Exon 4-6 splice } \\
\text { Exon } 4\end{array}$ & $\begin{array}{l}420 \mathrm{bp} \\
170 \mathrm{bp}\end{array}$ \\
\hline Exon 6 & $250 \mathrm{bp}$ \\
\hline Not I-Sma I (Pro & \\
\hline $\begin{array}{l}\text { Exon 4-6 } \\
\text { Exon } 4\end{array}$ & $\begin{array}{r}335 \mathrm{bp} \\
85 \mathrm{bp}\end{array}$ \\
\hline Exon 6 & \\
\hline
\end{tabular}

Figure 5. Probes used and predicted mRNA species from mRNA protection experiments. The positions of the mutations found by sequencing are shown by the asterisks. The CMV promoter and the bovine growth hormone polyadenylation signal (BGH) are derived from pCMV-4. respective cDNA (13) (Vellom D. C., and S. Camp, manuscript in preparation). Evidence for expression of all three splice options is obtained with mouse genomic DNA. In the case of transfection of human genomic DNA from control 1 and patient (EAD-2), evidence for splicing to exon 6 with the formation of a hydrophilic tetramer and splicing to exon 5 yielding a glycophospholipid-linked species is shown in Fig. 7. The hydrophilic tetramer sediments at $10.6 \mathrm{~S}$, whereas the glycophospholipidlinked species sediments at 5.6 S. Treatment with PIPLC removes the glycophospholipid, resulting in an increase in sedimentation

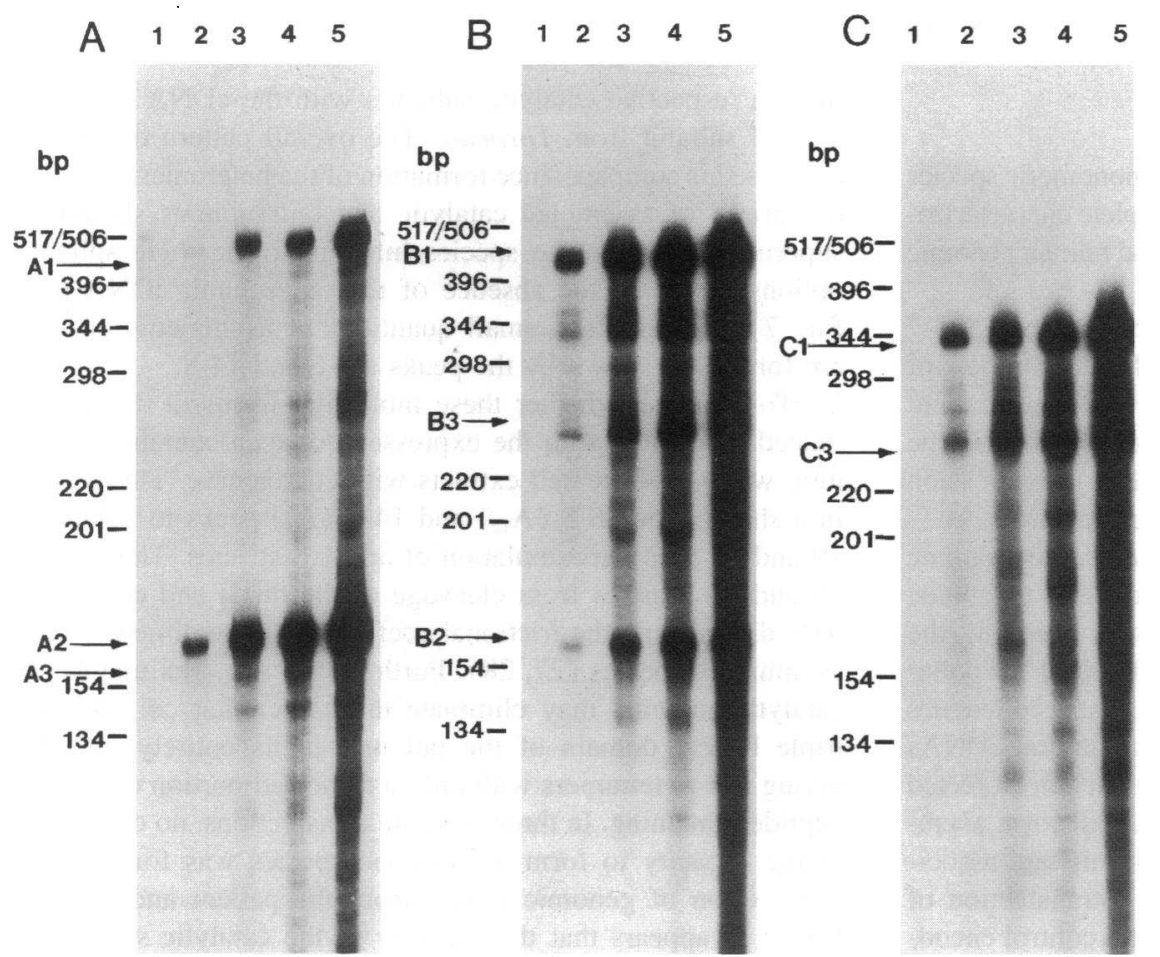

Figure 6. mRNA protection to identify alternative splicing. HEK cells were transiently transfected with all of the coding exons of the human $A C H E$ gene in PCVM-4. RNA was isolated for RNase protection. The probes used and mRNA species that were generated are depicted in Fig. 5. ( $A$ ) RNA from HEK cells transfected with $10 \mu \mathrm{g} \mathrm{pCMV}-4$ (24) derived plasmid constructs. Lane $1, \mathrm{CMV}$ vector control, $10 \mu \mathrm{g}$ RNA; lanes 2 and 3, the 4.7-kb SstII insert derived from the control 1 human placental library in the CMV plasmid: lane 2, $1 \mu \mathrm{g}$ RNA; lane 3, $5 \mu \mathrm{g}$ RNA; lanes 4 and 5, the 4.7-kb SstII insert is from the EAD-2 patient library. Lane 4, $1 \mu \mathrm{g}$ RNA; lane 5, $5 \mu \mathrm{g}$ RNA. The protection probe is genomic DNA from control 1 extending $420 \mathrm{bp}$ from the BamHI site in exon 4 to an Apal site in the intron between exons 4 and 6 (Fig. 5, probe $A$ ). ( $B$ ) As $B$ above, except the protection probe is genomic DNA from control 1 in which exons 4 and 6 are directly linked by loop-out mutagenesis to match one species of $A C H E$ cDNA. The probe extends 420 bp from the BamHI site in exon 4 to the Smal site in exon 6 (Fig. 5, probe $B$ ). ( $C$ ) As $B$ above, except the 335-bp probe extends from the NotI site in exon 4 to the SmaI site in exon 6 (Fig. 5, probe $C)$. Nucleic acid size estimates come from DNA standards and are only approximate. Major protected species are highlighted with horizontal arrows. The identifying markers A1-C3 are described in Fig. 5. 


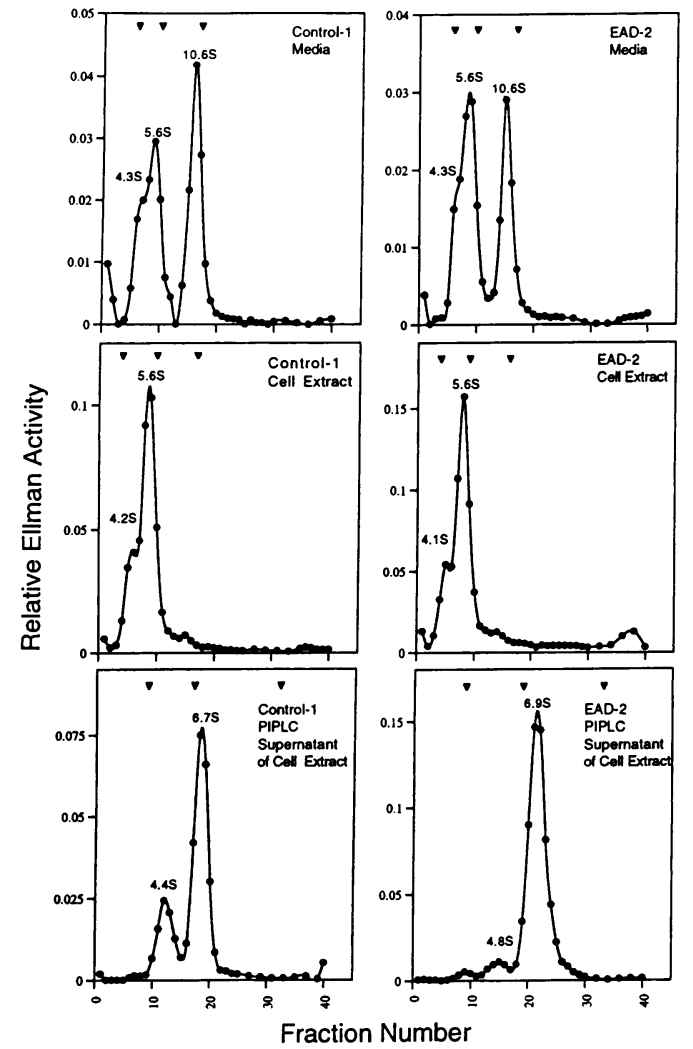

Figure 7. Sucrose density gradient centrifugation of AChE expressed in HEK cells from genomic clones of the human ACHE gene. (Left) Genomic DNA from control 1. (Right) Genomic DNA from patient EAD-2. In the upper four panels the gradients were centrifuged for 12 $h$, whereas a 20-h centrifugation was used for the panels in which the samples were treated with PIPLC. Sedimentation standards are denoted by filled triangles: bovine erythrocyte carbonic anhydrase B (3.3 S), E. coli alkaline phosphatase type III (6.1 S), and bovine liver catalase (11.4 S). The 4.4, 5.6, and 10.8 S species are monomer, dimer (glycophospholipid-linked and amphiphilic), and tetramer (hydrophilic) species of AChE. Treatment of the cell extract with PIPLC solubilizes the $5.6 \mathrm{~S}$ species and shifts its sedimentation to a value of 6.7-6.9 S with a concomitant loss of glycophospholipid.

coefficient from 5.6 S to 6.7-6.9 S. Candidate monomeric species are seen in lower abundance at $\leq 4.4 \mathrm{~S}$. A complete characterization of AChE species expressed from murine and human genomic DNA will be presented elsewhere.

In four separate transfections into either HEK or COS-7 cells, we find no consistent differences in the distribution of molecular species between control (control 1) and patient (EAD-2). This finding would argue against the regions in the 4.7-kb SstII fragment controlling different splice or expression patterns in the transfected cells for patients and controls.

Assembly of catalytic subunits with tail units. To examine the question of assembly of catalytic and collagen tail units, we cotransfected the above minigene constructs encoding the catalytic subunits with a cDNA encoding a subunit of the collagen-containing tail unit. Previously, Massoulié and colleagues $(17,19,22,23)$ have shown that both Torpedo and rat cDNAs encoding their respective catalytic subunits, when cotransfected with a cDNA encoding the Torpedo tail unit, will form asymmetric species in which the catalytic and tail units are associated. Fig. 8 shows a similar experiment of cotransfection of human genomic clones from either a patient or a control encod-

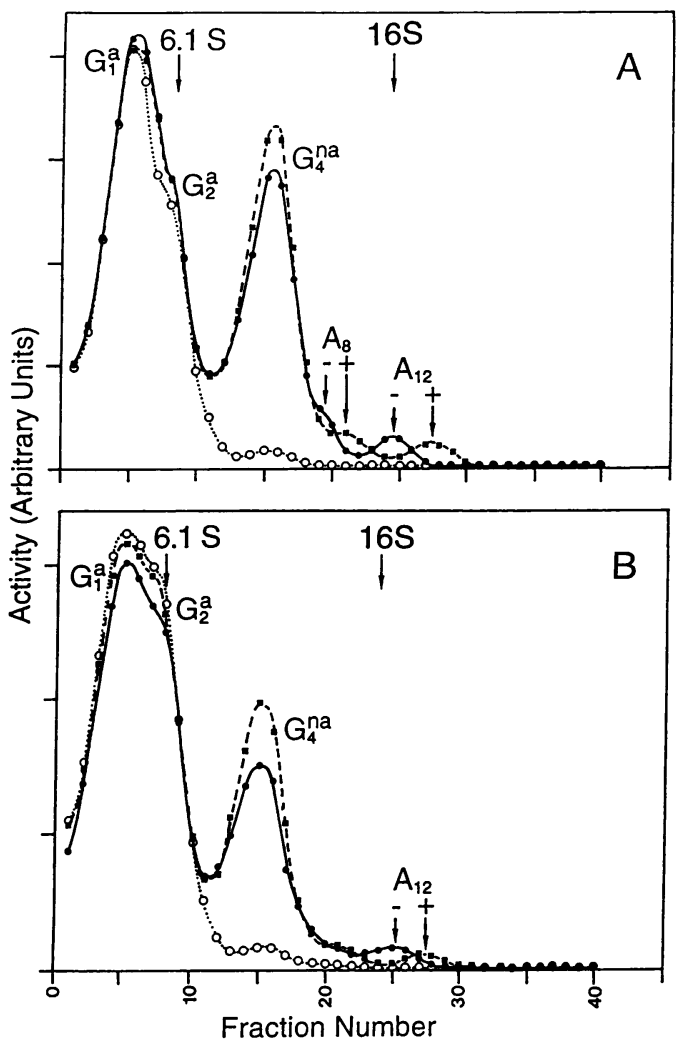

Figure 8. Acetylcholinesterase species extracted from COS-7 cells after coexpression of the genes encoding the human catalytic subunit and Torpedo tail subunit. (A) Genomic clone of ACHE from EAD-2. -- -, AChE activity extracted $48 \mathrm{~h}$ after coexpression; - - extracted AChE activity after treatment with collagenase; $\bigcirc-O$, extracted AChE activity after expression of the catalytic subunit alone. $A_{12}$ and $A_{8}$ represent the asymmetric-collagen containing forms of $\mathrm{AChE}$, collagenase induces a characteristic increase in sedimentation coefficient in these forms $(23)$, the $(-,+)$ symbols associated with $A_{8}$ and $A_{12}$ show this increase; $G_{4}{ }^{n a}$, a tetrameric nonamphiphilic form; $G_{2}{ }^{a}$ and $\mathrm{G}_{1}{ }^{\mathrm{a}}$ are dimeric and monomeric amphiphilic forms.

ing the respective catalytic subunits with the cDNA encoding the tail subunit from Torpedo. The overall pattern of species expressed is complex since formation of the heteromeric species comprised of assembled catalytic and tail subunits should be superimposed upon the species inherent to the three splicing options shown in the absence of the tail subunit cDNA (see Fig. 7). Nevertheless, small quantities of asymmetric species are formed as shown by the peaks at 16 and $14 \mathrm{~S}$.

To establish whether these molecular forms of AChE are indeed associated with the expressed collagen-containing subunit, we treated the cell extracts with collagenase. This results in a shift of the $16 \mathrm{~S}\left(\mathrm{~A}_{12}\right)$ and $14 \mathrm{~S}\left(\mathrm{~A}_{8}\right)$ peaks to values of 19 and $16 \mathrm{~S}$ and accumulation of an $11 \mathrm{~S}$ species. The shift to 19 and $16 \mathrm{~S}$ arises from cleavage of the distal end of the tail unit, diminishing the frictional coefficient of the dimensionally asymmetric species $(27,28)$. Further cleavage proximal to the catalytic subunits may eliminate the associating collagenous, triple helical domain of the tail unit in its entirety, thereby giving rise to tetramers with only a truncated portion of the tail peptide remaining. In three separate transfections, no difference in the capacity to form asymmetric species was found upon transfection of genomic clones from the patient and control. Hence, it appears that the capacity of the catalytic subunit in 


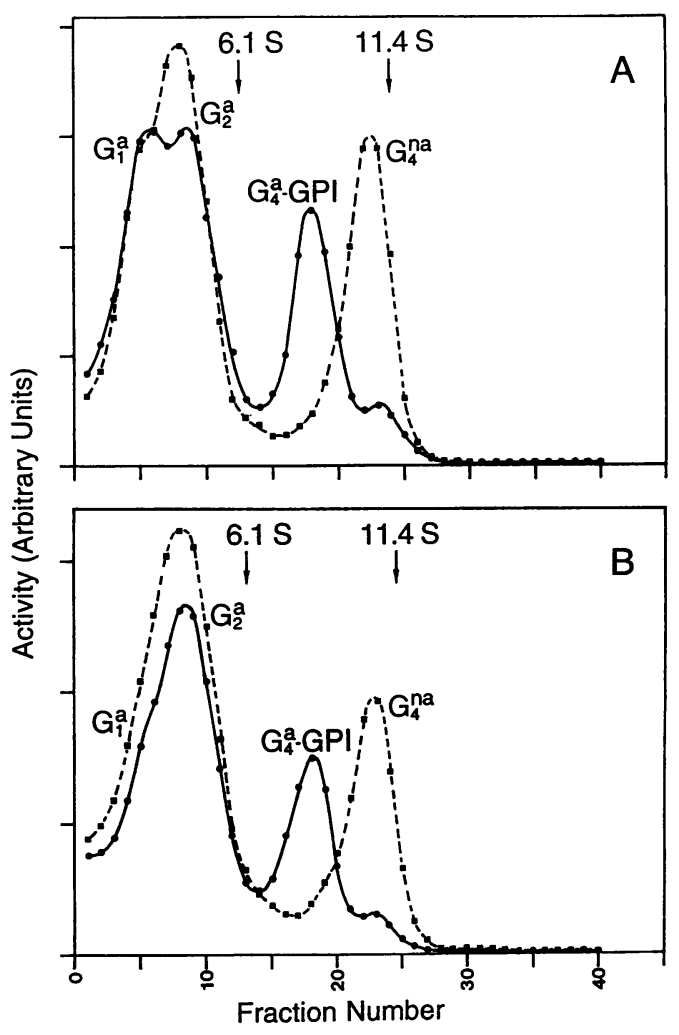

Figure 9. Acetylcholinesterase species extracted from COS-7 cells after coexpression of the gene encoding the catalytic subunit of human acetylcholinesterase and a chimeric cDNA. The chimera encodes the aminoterminal sequence of the Torpedo collagen tail unit linked to a signal sequence for glycophospholipid conjugation (21). Association of the expressed catalytic subunit with the tail unit gives rise to a tetrameric $\mathrm{G}_{4}{ }^{\mathrm{a}}$ species whose sedimentation coefficient increases from $8.8 \mathrm{~S}$ to 10.5 S after treatment with PIPLC.

the EAD patient to assemble with a tail unit is unaltered when expression is carried out in this cell culture system.

Duval et al. (19) have constructed a chimera of the tail subunit in which cDNA encoding the amino-terminal portion of the tail unit is linked to a sequence encoding the signal sequence for glycophospholipid attachment. Since the aminoterminal sequence is sufficient for the disulfide linkage, treatment of the expressed enzyme with PIPLC should remove the conjugated lipid. A shift in mobility of the AChE species would be diagnostic of association, presumably through disulfide linkage, between heteromeric subunits. We find substantial expression of the heteromeric species and the appropriate increase in sedimentation coefficient upon treatment with the phospholipase treatment (Fig. 9). Again, no difference in pattern of expressed species is observed when patient and control genomic DNA expression constructs are used in the cotransfection.

\section{Discussion}

We have examined the structure of the human gene encoding the catalytic subunit of $\mathrm{AChE}$, its expression under a variety of conditions, and have accumulated considerable evidence to establish that the $A C H E$ gene and expression of the AChE catalytic subunits do not differ between EAD patients and controls. These findings are based on the sequence of the gene itself and the capacity of gene products to assemble with the tail unit expressed in the same cells.

To examine gene structure, we analyzed restriction fragment patterns from patient and control DNA. The absence of differences in the restriction patterns argues against major rearrangements of DNA but cannot exclude either point mutations or a sequence change in a small region of the DNA. To examine these possibilities, we conducted S-1 nuclease protection studies in the region between exons 4 and 6 . It is this region where alternative mRNA splicing occurs to form species of $\mathrm{AChE}$ capable of disulfide bond formation with the collagen-containing subunit. Exon 6 also encodes the cysteine that links the catalytic and tail subunits. Our analysis reveals that DNA from one control individual will fully protect the labeled antisense mRNAs generated from two of the patients but not from another control individual. Thus, nuclease protection uncovers an allelic difference, but not one that correlates with the EAD disorder.

To examine these allelic differences further, we sequenced the $0.85-\mathrm{kb}$ region between exons 4 and 6 and were able to find two sequence disparities located in introns. One is a 3-bp deletion, whereas the other is a single base change. Other point mutations in the human $A C H E$ gene of codons 322 and 561 have been reported (29). The former is a low frequency mutation $(\sim 0.05)$. At 561, CCG appears in EAD-2 and EAD-3 and two of the three controls we sequenced; one control had CGG. Sequencing has not been carried out on the other patient DNA or on DNA from close family members; thus it is not possible to establish potential linkages. None of the seven patients examined by one of us (A. G. E.) had affected parents, suggesting a new autosomal dominant or more likely an autosomal recessive disorder.

The second phase of the study entailed expression of the cloned genes from patients and controls. The compact nature of the $A C H E$ gene makes it well suited for this endeavor. A size-selected library enabled us to clone a $15-\mathrm{kb}$ Bg1II fragment from one of the patients. Expression of an internal 4.7-kb SstII subfragment from patient and control DNA that included the entire open reading frame (Fig. 1) was undertaken. All three mRNA species representing the splice alternatives are evident (Fig. 6). The dimeric glycophospholipid-linked enzyme, reflecting the exon 4-5 splice, and soluble dimeric and tetrameric species, reflecting the exon 4-6 splice, are expressed in considerable abundance (Fig. 7). Smaller quantities of monomeric and dimeric species that may result from the retention of the intron between exons 4 and 5 are also evident. No differences in the ratio of distribution of species emerge when expression of genomic DNA from controls and EAD patients is compared.

Cotransfection of genomic DNA encoding the catalytic subunits with a Torpedo cDNA encoding the collagenous tail subunit results in the formation of the asymmetric species in which tetramers of the human catalytic subunit are associated and presumably disulfide-linked with each of three strands of a triple-helical tail unit. The $16 \mathrm{~S}\left(\mathrm{~A}_{12}\right)$ species likely reflects three tetramers, each tetramer disulfide linked to a strand of the triple helical tail, whereas the $14 \mathrm{~S}$ species contains only two tetramers. A chimera encoding the amino-terminal portion of the tail unit linked to a carboxyl-terminal glycophospholipid signal, when transfected with catalytic subunits, also yields a heteromeric species of tetrameric catalytic subunits with the constructed structural subunit. Assembly of patient and control catalytic subunits is identical when their encoding genes are cotransfected with either the native or chimeric Torpedo subunit.

Neither the $A C H E$ gene structure nor the population of ex- 
pressed AChE species provide evidence for an alteration in structure or expression capacity of the catalytic subunit. These findings lead to the alternatives: $(a)$ an altered structure of the collagen-containing tail subunit or $(b)$ an alteration in a protein involved in promoting the assembly between the catalytic subunit and tail unit.

The collagen-containing tail unit presumably exists as a triple helix. The multiplicity of collagen containing bands seen with the purified species in Torpedo and Electrophorus suggests that the tail may be composed of nonidentical subunits $(10,30$, 31). Accordingly, as with many of the collagens, we should expect each subunit to be encoded by a separate gene. In fact, multiple cDNAs encoding candidate tail subunits have been identified in Torpedo (10). If a single mutation is responsible for the lack of assembly, this mutation either must occur in the subunit exerting dominant control in establishing the intersubunit disulfide or redundancy among subunits enabling another subunit to replace the dominant subunit is absent.

If a disulfide exchange protein serving to catalyze assembly of the head and tail units is functionally deficient, it would be surprising that other disulfide-linked proteins are not affected in these patients. The assembly process presumably requires an appropriate recognition sequence $(17,19)$, but assembly is not specific to the differentiated muscle cell as it can be achieved in transfected human embryonic kidney cells and monkey kidney cells.

Our findings narrow the structural basis for the genetic aberration in this congenital myasthenic syndrome and the structure of the tail unit now emerges as the likely target for study. This should add incentive to cloning the gene encoding this lowabundance presumably synapse-specific protein from mammalian muscle. Whether the alteration arises from a mutation in the gene encoding the tail subunits or the absence of functional expression of a gene product responsible for assembly of the catalytic and tail units is unknown. This question should be resolved when clones of the human tail subunit become available.

\section{Acknowledgments}

We thank Dr. Martin Low of Columbia University for the gift of recombinant PIPLC.

This work was supported by a grant from the Muscular Dystrophy Association and U. S. Public Health Service grant GM-18360.

\section{References}

1. Engel, A. G., E. H. Lambert, and M. R. Gomez. 1977. A new myasthenic syndrome with end-plate acetylcholinesterase deficiency, small nerve terminals, and reduced acetylcholine release. Ann. Neurol. 1:315-330.

2. Hutchinson, D. O., A. G. Engel, T. J. Walls, S. Nakano, S. Camp, P. Taylor, C. M. Harper, and J. M. Brengman. 1993. The spectrum of congenital end-plate acetylcholinesterase deficiency. Ann. NY Acad. Sci. 681:469-486.

3. Hutchinson, D. O., T. J. Walls, S. Nakano, S. Camp, P. Taylor, C. M. Harper, R. V. Groover, H. A. Peterson, D. G. Jamieson, and A. G. Engel. 1993. Congenital end plate acetylcholinesterase deficiency. Brain. 116:633-653.

4. Jennekens, F. G. I., L. F. Hesselmans, H. Veldman, E. N. Jansen, F. Spaans, and P. C. Molenaar. 1992. Deficiency of acetylcholine receptors in a case of endplate acetylcholinesterase deficiency: a histochemical investigation. Muscle and Nerve. 15:63-72.

5. Getman, D. K., S. Camp, J. Eubanks, G. Evans, and P. Taylor. 1992. The human gene encoding acetylcholinesterase is located on the long arm of chromosome 7. Am. J. Hum. Genet. 51:170-177.

6. Ehrlich, G., E. Viegas-Pequignot, D. Ginzberg, L. Sindel, H. Soreq, and H. Zakut. 1992. Mapping the human acetylcholinesterase gene to chromosome $7 \mathrm{q} 22$ by fluorescent in situ hybridization coupled with selective PCR amplification from a somatic hybrid cell panel and chromosome-sorted DNA libraries. Genomics. 13:1192-1197.

7. Gibney, G., K. MacPhee-Quigley, B. Thompson, T. Vedvick, M. G. Low, S. S. Taylor, and P. Taylor. 1988. Divergence in primary structure between molecular forms of acetylcholinesterase. J. Biol. Chem. 263:1140-1145.

8. Sikorav, J. L., N. Duval, A. Anselmet, S. Bon, E. Krejci, C. Legay, M. Osterlund, B. Reimund, and J. Massoulié. 1988. Complex alternative splicing of acetylcholinesterase transcript in Torpedo electric organ: primary structure of the precursor of the glycolipid-anchored dimeric form. EMBO (Eur. Mal. Biol. Organ.) J. 7:2983-2993.

9. Maulet, Y., S. Camp, G. Gibney, T. L. Rachinsky, T. J. Ekström, and P. Taylor. 1990. A single gene encodes glycophospholipid-anchored and asymmetric acetylcholinesterase forms: alternative coding exons contain inverted repeat sequences. Neuron. 4:289-301.

10. Massoulié, J., L. Pezzementi, S. Bon, E. Krejci, and F. M. Vallette. 1993 Molecular and cellular biology of the cholinesterases. Prog. Neurobiol. 41:3191.

11. Taylor, P., and Z. Radic. 1994. The cholinesterases: from gene to protein. Annu. Rev. Pharmacol. 34:281-320.

12. Li, Y., S. Camp, T. L. Rachinsky, D. K. Getman, and P. Taylor. 1991 Gene structure of mammalian acetylcholinesterase: alternative exons dictate tissue-specific expression. J. Biol. Chem. 266:23083-23090.

13. Li, Y., S. Camp, and P. Taylor. 1993. Tissue-specific expression and alternative mRNA processing of the mammalian acetylcholinesterase gene. $J$. Biol. Chem. 268:5790-5797.

14. Karpel, R., R. Ben Aziz-Aloya, M. Sternfeld, G. Ehrlich, D. Ginzberg, P. Tarroni, F. Clementi, H. Zakut, and H. Soreq. 1994. Expression of three alternative acetylcholinesterase messenger RNAs in human tumor cell lines of different tissue origins. Exp. Cell. Res. 210:268-277.

15. Li, Y., S. Camp, T. L. Rachinsky, C. Bongiorno, and P. Taylor. 1993. Promoter elements and transcriptional control of the mouse acetylcholinesterase gene. J. Biol. Chem. 268:3563-3572.

16. Legay, C., S. Bon, and J. Massoulié. 1993. Expression of a cDNA encoding the glycophospholipid-anchored form of rat acetylcholinesterase. FEBS (Fed. Exp. Biol. Soc.) Lett. 315:163-166.

17. Krejci, E., F. Coussen, N. Duval, J. M. Chatel, C. Legay, M. Puype, J. Vandekerckhove, J. Cartaud, S. Bon, and J. Massoulié. 1991. Primary structure of a collagenic tail subunit of Torpedo acetylcholinesterase: co-expression with catalytic subunit induces the production of collagen-tailed forms in transfected cells. EMBO (Eur. Mol. Biol. Organ.) J. 10:1285-1293.

18. MacPhee-Quigley, K., T. S. Vedvick, P. Taylor, and S. S. Taylor. 1986. Profile of disulfide bonds in acetylcholinesterase. J. Biol. Chem. 261:1356513570.

19. Duval, N., E. Krejci, J. Grassi, F. Coussen, J. Massoulié, and S. Bon. 1992. Molecular architecture of acetylcholinesterase collagen-tailed forms; construction of a glycolipid-tailed tetramer. EMBO (Eur. Mol. Biol. Organ.) J. 11:3255-3261.

20. Pope, J. H., W. Scott, and D. J. Moss. 1974. Cell relationships in transformation of human leukocytes by Epstein-Barr virus. Int. J. Cancer 14:122-129.

21. Andersson, S., D. L. Davis, H. Dahlback, H. Jornvall, and D. W. Russell. 1989. Cloning, structure, and expression of the mitochondrial cytochrome P-450 sterol 26-hydroxylase, a bile acid biosynthetic enzyme. J. Biol. Chem. 264:82228229.

22. Duval, N., J. Massoulié, and S. Bon. 1992. H and T subunits of acetylcholinesterase from Torpedo, expressed in COS cells, generate all types of globular forms. J. Cell. Biol. 118:641-653.

23. Legay, C., S. Bon, P. Vernier, F. Coussen, and J. Massoulié. 1993. Cloning and expression of a rat acetylcholinesterase subunit: generation of multiple molecular forms and complementarity with a Torpedo collagenic subunit. J. Neurochem. 60:337-346.

24. Ausubel, F. M., R. Brent, R. E. Kingston, D. D. Moore, J. G. Seidman, J. A. Smith, and K. Strahl. (eds.) 1987. Current Protocols in Molecular Biology. John Wiley \& Sons, New York.

25. Chomczynski, P., and N. Sacchi. 1987. Single step method of RNA isolation by acid guanidinum thiocyanate-phenol-chloroform extraction. Anal. Biochem. 162:156-159.

26. Feinberg, A. P., and B. Vogelstein. 1984. A technique for radiolabeling DNA restriction endonuclease fragments to high specific activity. Anal. Biochem. 137:266-267.

27. Bon, S., and Massoulié, J. 1978. Collagenase sensitivity and aggregation properties of Electrophorus acetylcholinesterase. Eur. J. Biochem. 89:89-94.

28. Lee, S. L., and P. Taylor. 1982. Structural characterization of the asymmetric $(17+13) \mathrm{S}$ species of acetylcholinesterase from Torpedo. J. Biol. Chem. 257:12292-12301.

29. Bartels, C., T. Zelinsky, and O. Lockridge. 1993. Mutation at codon 322 in the human acetylcholinesterase (ACHE) gene accounts for YT blood group polymorphism. Am. J. Hum. Genet. 52:928-936.

30. Rosenberry, T. L., and J. M. Richardson. 1977. Structure of $18 \mathrm{~S}$ and 14 $S$ acetylcholinesterase. Identification of collagen-like subunits that are linked by disulfide bonds to catalytic subunits. Biochemistry 16:3550-3558.

31. Rosenberry, T. L., P. Barnett, and C. Mays. 1980. The collagen-like subunits of acetylcholinesterase from the eel Electrophorus electricus. Neurochem. Int. 2:135-147. 